\title{
Evaluation of Maximum Biting Force in Two Different Attachment Systems (Bollard vs. Ball and Socket) Retaining Mandibular Overdenture: A Split-mouth Design
}

\author{
Reham Tharwat Kamal Elbeheiry*, Gehan Fekry Mohamed, Amr Mohamed Ismail Badr \\ ${ }^{1}$ Department of Removable Prosthodontics, Faculty of Dentistry, Minya University, Minya, Egypt
}

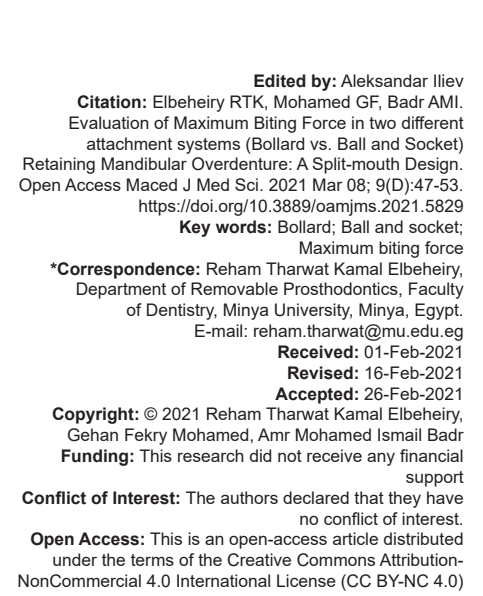

Abstract

AIM: The study was conducted to evaluate maximum biting force (MBF) in two different attachment systems (bollard a vs. ball and socket attachment) retaining mandibular overdenture using a split-mouth design

SUBJECTS AND METHODS: Twelve completely edentulous patients received complete dentures and after adaption of the patient with the new denture, 24 implants were inserted in the canine region using two-stage surgical technique and conventional loading protocol. Six patients received the Bollard attachment at the right side and the Ball and Socket at the left side. Moreover, the other six patients received the bollard attachment at the left side and the ball and socket attachment at the right side. Each patient was treated according to split-mouth design. Insertion of each of the attachment type was assigned randomly. Using occlusal force meter instrument, MBF was measured immediately after loading (0), after 6 months (6), and after 12 months (12).

RESULTS: Significant statistical differences $(p<0.05)$ were obvious in in MBF between Attachment $(1)$ and Attachment (2) immediately after loading (0 months), after 6 months (6) and after 12 months (12) follow-up visits.

CONCLUSION: Mandibular implant retained overdenture received Bollard abutment that retained with the denture by the help of resilient liner "Retention.sil"* without housing have higher biting forces than mandibular implant retained overdenture with ball abutment where the plastic house was picked up by monomer free self-cured acrylic resin.

\section{Introduction}

Edentulism is defined as "the state of being without any natural permanent teeth. It is an irreversible condition that is evident in age groups of 65 years and older and was previously considered part of the normal aging process [1].

The glossary of implant dentistry, define implantretained prosthesis as any prosthesis that is completely or partially supported by implant or implants [2].

The clinical outcome of implant retained overdenture is significantly better than that achieved with conventional dentures, especially when patients are experiencing technical problems because of compromised prosthesis retention or stability. Mostly, efficient retention and stability are easily achieved by a fixed restoration or using overdenture's attachments instead of depending on the physical means of retention with conventional dentures [3], [4], [5].

The design of implant-supported overdentures varies according to the method of attachment and amount of support to be desired from implant and ridge mucosa. Various attachments have been advocated for retaining overdentures to implants. The commonly used types are bars, ball and sockets, locators, magnets, OT equators, and telescopic crowns [6].

The advantages of ball and socket attachment are simplicity in design, ease of use and maintenance, low cost, varying degrees of retention, wide range of movement, great patient satisfaction, and used to increase retention of implant overdenture prostheses with regard to optimizing stress and minimizing denture movement [7]. The Bollard (Poller) is a new resilient telescopic attachment employed in implant supported removable denture cases [8].

The use of long-term soft denture lining (LTSDLs) is characterized by markedly improved speech and ability to chew, significantly reduced feelings of pain and oral soreness under the dentures, better retention and stability of the dentures, an increase in psychological comfort and longer denture wearing times [9], [10], [11].

Retention.Sil was introduced according to its chemical composition that is based on Polyvinylsiloxane (PVS) that has three options according to the detachment force desired (200, 400, and $600 \mathrm{gf})$ [12]. 
The maximum biting force (MBF) is considered to be the force that generated by the greatest effort of the mandibular teeth against the maxillary teeth when the jaw is closed under the effect of the jaw muscles as a result of the coordination between the components of the masticatory system. Masticatory muscles such as Masseter, Temporalis, and Medial Pterygoid play an important role in the closure of the jaw and hence the biting forces [13], [14].

The masticatory force is an important indicator of the functional state of all the masticatory system. The biting forces are used to understand the biomechanical principles of masticatory system and feedback of prosthetic treatment. Furthermore, the MBF measurement is very important for the treatment of dysfunction of the stomatognathic system [15]. Their measurement indicates, quantitatively, the muscular efficiency of the dental tightening, thereby enabling effective detection of possible masticatory alterations [16], [17]. Their values are influenced by many factors. Individual characteristics, the recording device, bruxist individuals, and the posture of the individual's head are some of these factors [14], [18]. This variable is directly related to individuals' quality of life since the greater the masticatory capacity and efficacy, the better the food fragmentation will be and the better the digestion [19]. Furthermore, the maximum occlusal force can significantly increase with the use of LTSDLs [20], [21].

The aim of the study was to evaluate MBF in two different attachment systems (Bollard a vs. Ball and Socket attachment) retaining mandibular overdenture using a split-mouth design.

\section{Subjects and Methods}

\section{procedures \\ Patient selection and pre-surgical}

All treatment procedures, complications, and treatment outcomes were explained for patients. Informed consent that lay down by research ethics committee at Faculty of Dentistry-Minya University was submitted by the patients to participate in the study before data collection.

Twelve completely edentulous patients (six males and six females) were selected from those attending the outpatient clinic of Removable Prosthodontics Department-Faculty of DentistryMinya University with the following inclusion criteria: Cooperative patient, patient free from any systemic diseases that may affect osseointegration, firm healthy mucosal coverage of the edentulous ridge, sufficient bone dimensions at the anterior mandibular segment should be $16 \mathrm{~mm}$ height and $5 \mathrm{~mm}$ width at least, inter-arch space not $<22 \mathrm{~mm}$, Angle's Class I maxillomandibular relationship, and no tempromandibular joint disorders. Moreover, the following exclusion criteria: Patients with bad habits (i.e., Bruxism), heavy smokers, alcohol consumption patient, patients on long-term steroids or immunosuppressive drugs or bisphosphonates, and patients who received radiotherapy to the head or neck region.

Twelve complete dentures were constructed following the conventional denture fabrication procedures. Primary impressions were taken with irreversible hydrocolloid material (Cavex CA37, Normal Set, Holland) to obtain study casts. Final impressions using a border molded autopolymerizing acrylic special trays (Palapress Vario Heraeus Kulzer, Hanau, Germany) and non-eugenol Zinc-oxide and eugenol (Cavex impression paste, Holland) to obtain the master casts.

Waxing-up of the metal framework making into consideration not to cover the site of the canine in both sides. Investing and casting with base-metal alloy were made according to the manufacturer's instructions. Intraoral metal framework try-in and jaw relation were done. The master casts were mounted on a semi-adjustable articulators (HANAU, Wide; Whip Mix Corporation, Farmington Ave, Louisville, $\mathrm{KY}$, USA). For mounting the maxillary casts, face bow records were used. For mounting the mandibular casts, centric relation records with (check-bite technique) at the proper vertical dimension. Protrusive and lateral records were taken to adjust the condylar and lateral guidance of the articulator. Artificial acrylic teeth (Vitapan; Vita Zahnfabrik, Badackingen, Germany) were set in bilateral occlusal balance. Overcontoured waxing up was made at the canine area in both sides. Intraoral waxed try-in was done.

Flasking and wax elimination were accomplished. Packing of the overdenture was done using heat-cured acrylic resin (Acrostone, WHW, England). After that, the processing was accomplished with the conventional method. The dentures were delivered to the patients after finishing and polishing.

Patients were given instructions for denture hygiene. After 1 week, denture inspection and occlusal adjustments were made and clinical remounting during the follow-up session. The patients were recalled for at least 3 months before implant insertion.

\section{Surgical procedures}

The mandibular complete dentures were duplicated into clear acrylic resin to be used as surgical stents. Using cone beam computerized tomography machine (Scanora3D, Sorredex-Finland, $15 \mathrm{~mA}$, $85 \mathrm{KV}$ ) a pre-operative radiograph was taken before implant placement with and without the stent to assess the residual alveolar bone quality and quantity. 
The patients were given a pre-operative oral antibiotic $48 \mathrm{~h}$ before surgery then continued for another $72 \mathrm{~h}$ after surgery. Bilateral infiltration anesthesia to the labial and lingual vestibules at intra-foraminal area was given to the patients.

After reflection of the flap, the stent was applied over the mandibular ridge and used to slightly retract the soft tissue. The standard technique of implant insertion was followed (low speed drilling with high torque motor, successive drilling, and double coolant under strict aseptic condition). Each patient received two implants of $3.5 \mathrm{~mm}$ diameter and $14 \mathrm{~mm}$ length (Sky implant system, REF: nsky3514, Bredent medical GmbH \& Co.KG Weissenhorner Str. 2 | 89250 Senden | Germany) at the canine region bilaterally. The implants were inserted using two-stage surgical technique and conventional loading protocol. Implants were manually inserted with the torque wrench until flushing with bone level. External coolant was applied during tightening the implant to avoid overheating the bone. Implants remained submerged for 3 months. Post-surgical instructions and antibiotics were prescribed for each patient.

All patients were randomly divided into two equal groups according to the site of implant attachment position either right or left. Six patients received the Bollard attachment at the right side and ball and socket attachment at the left side. Moreover, the other six patients received the Bollard attachment at the left side and the ball and socket attachment at the right side. Each patient was treated according to split-mouth design.

\section{Attachment 1 (bollard attachment)}

Received Bollard abutment (TiSi.snap 5/3 REF:TISIOY53, SKY implant system, Bredent medical GmbH \& Co.KG Weissenhorner Str. 2 | 89250 Senden | Germany) and retained with the denture by the help of resilient liner "Retention.Sil 600" (65 SH, 600 g/6 Newton, REF:580 RTS 65, SKY implant system, Bredent medical GmbH \& Co.KG Weissenhorner Str. 2 | 89250 Senden | Germany) without housing.

\section{Attachment 2 (ball and socket attachment)}

Received Ball abutment (2,2 abutment, $4 \mathrm{~mm}, \mathrm{DH} 2 \mathrm{~mm}$, REF 46000042, SKY implant system, Bredent medical GmbH \& Co.KG Weissenhorner Str. 2 | 89250 Senden | Germany), where the plastic house was picked up by monomer free self-cured acrylic resin (Figure 1).

\section{Prosthetic procedures}

After 3 months, the implants were exposed using a tissue punch. Then, the bollard abutments and the ball abutments were fastened to the implants intraorally using the torque wrench.

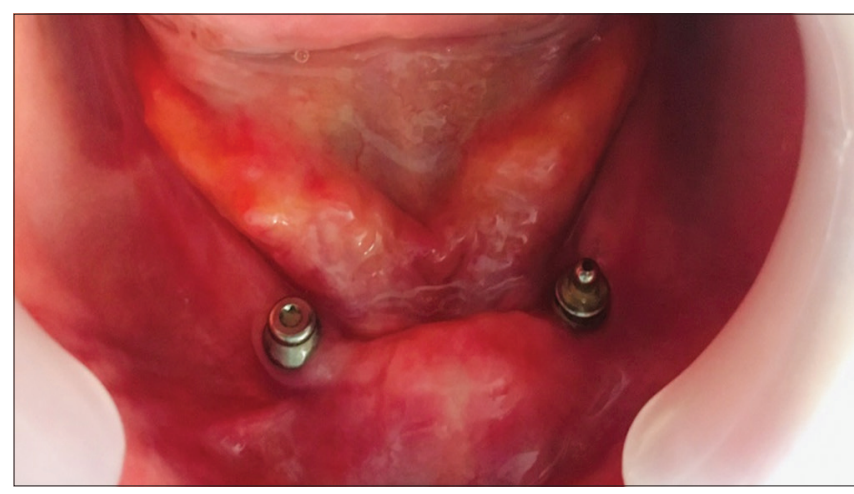

Figure 1: Bollard abutment versus ball abutment

The denture's fitting surface opposite the abutments position was prepared to allow for complete seating without interference. For the ball abutments (Group 2), the plastic house was picked up by monomer free self-cured acrylic resin (Acrostone Cold Cure Acrylic Resin, Acrostone Co., England) at dough stage. A small window was created at the lingual flange opposite to the abutment to allow for the escape of excess pick-up material. Whereas for the bollard abutments (Group 1), the created recesses were then painted with primer liquid (Multisil-Primer 5 ml, REF 5200100 4, SKY implant system, Bredent medical GmbH \& Co.KG Weissenhorner Str. 2 | 89250 Senden | Germany) provided with Retention.Sil kit (Figure 2). After drying of the primer, Retention.Sil 600 paste was then filled up to the top by injection from its auto-injected cartilage, the denture was inserted into the patient mouth and asked the patient to close into centric occlusion $3 \mathrm{~min}$ to ensure that it was fitted into its place over the bollard abutment (Figure 3). After that, the denture was removed and the excess was removed then finished with the special silicone trimmer $(4.1 \mathrm{~mm}$, REF SKY-DR 41, SKY implant system, Bredent medical GmbH \& Co.KG Weissenhorner Str. 2 | 89250 Senden | Germany).

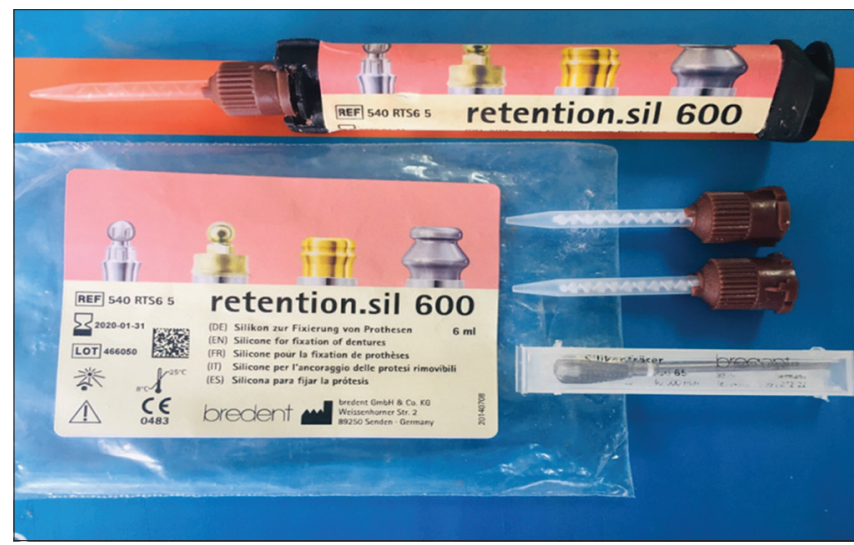

Figure 2: Retention. Sil 600 kit

The overdenture was delivered to the patient and accurate fitting on the abutments was insured (Figure 4). 


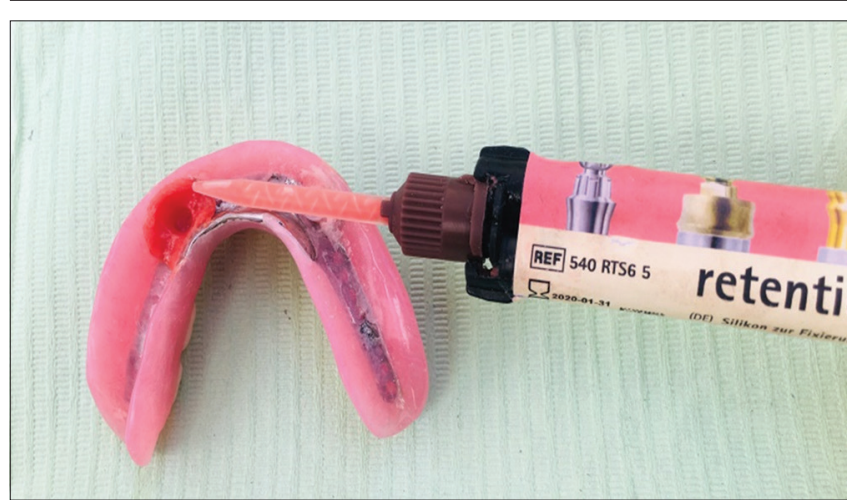

Figure 3: Loading of Retention.Sil 600 paste by its auto-injected cartilage into the overdenture

\section{Assessment of MBF}

The MBFs were measured with an occlusal force meter instrument (model GM, NaGONO Keiki Seisakusho, LTd., J. Morita Corporation,

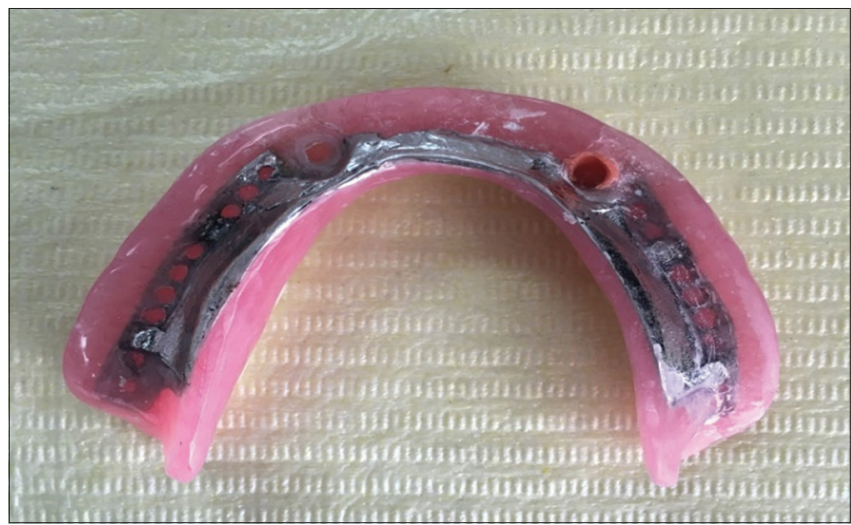

Figure 4: Fitting surface of mandibular overdenture with the plastic housing of the ball abutment and retention.sil around the bollard abutment

33-18-3-Chome-Torumi-Cho Suita City, Osaka 5648650 , Japan). The instrument consisted of a hydraulic pressure gauge and a biting element $(17 \mathrm{~mm}$ in width and $5.4 \mathrm{~mm}$ in height) made of a vinyl material encased in a disposable plastic tube, as shown in Figure 5.

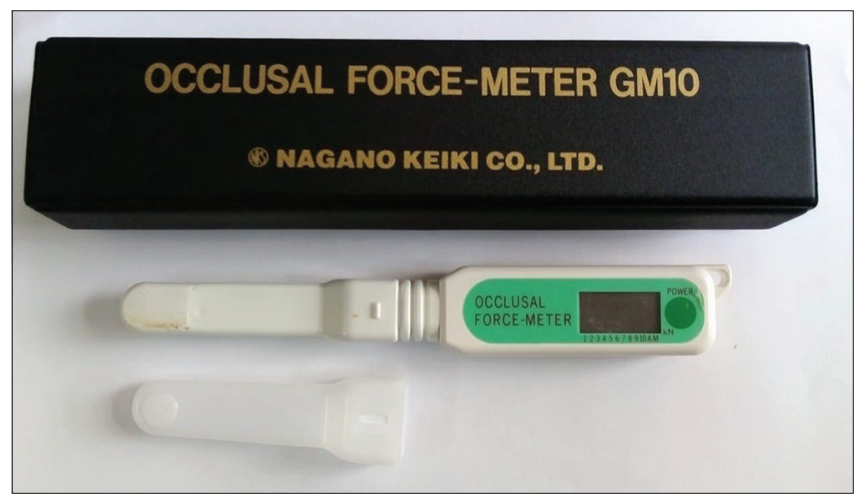

Figure 5: Occlusal force-meter

Before the actual data collection, all patients were allowed to be familiar with the measurement procedure and the instruments. During measurements, the patient was seated in an upright position, looking forward and head in unsupported position. The plastic tube that covered the arm of the occlusal force meter sensor device was inserted into the patient mouth and he asked to bite on it slowly. The recorded force during maximal clenching was obtained with one bite force meter placed between pairs of opposing teeth at one side at the area of $2^{\text {nd }}$ premolar/first molar where there is more number of occlusal contacts with strong determinant of muscle action and subsequent great bite force with $45 \mathrm{~s}$ intervals between successive bites then changing to the contralateral side to check the occlusal force. None of the patients experienced any discomfort or pain during biting on the occlusal force meter instrument. The MBF was displayed digitally on the screen of a computerized interface in Newton (Figure 6).

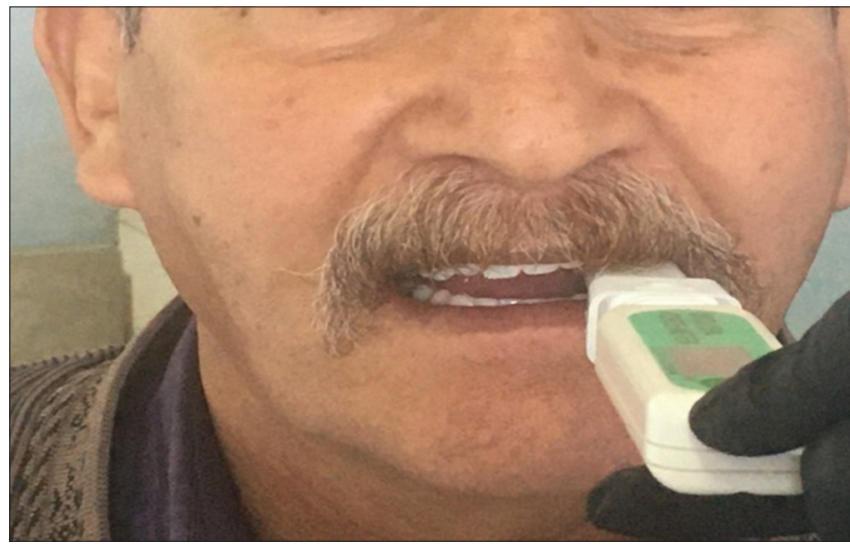

Figure 6: Measurement of maximum biting force

During performance, the patient maintained the desired level of biting force during all the test period and a buzzer sound will be heard if the biting force has exceeded the set-point. For each patient at each follow up visit, ten records of the right and left sides were collected.

Measurements of MBF were done for both Attachment (1) and Attachment (2) immediately after loading (0), after 6 months (6), and after 12 months (12) for each patient, using the instrument.

\section{Statistical analysis}

The data were collected, tabulated, and statistically analyzed by SPSS (SPSS Inc., Chicago, IL, USA). Mann-Whitney test was used to compare between groups, Friedman test was used to compare follow-up readings in single group.

\section{Results}

The mean values and standard deviations of the MBF in Attachment (1) (Bollard attachment) were $75.7 \pm 1.4,97.8 \pm 2.08$, and $168.6 \pm 22.1$ immediately 
Table 1: Descriptive statistics and comparison between Attachment (1) (Bollard attachment) and Attachment (2) (Ball attachment) regarding maximum biting force in (Newton)

\begin{tabular}{llll}
\hline Maximum biting force & Attachment (1) & Attachment (2) & p-value \\
\hline Immediately after loading & & & \\
$\quad$ Range & $74-78.5$ & $60.7-74.6$ & $0.001^{*}$ \\
$\quad$ Mean \pm SD & $75.7 \pm 1.4$ & $66.09 \pm 4.7$ & \\
After 6 months & & & \\
$\quad$ Range & $94.8-99.86$ & $82.03-86.78$ & $0.001^{*}$ \\
$\quad$ Mean \pm SD & $97.8 \pm 2.08$ & $84.1 \pm 2.01$ & \\
After 12 months & & & \\
$\quad$ Range & $128.8-188.9$ & $82.1-117.4$ & $0.001^{*}$ \\
$\quad$ Mean \pm SD & $168.6 \pm 22.1$ & $94.5 \pm 10.8$ & \\
p & $0.001^{*}$ & $0.001^{*}$ & \\
${ }^{*}$ Significant difference if $(p>0.05)$, values marked with (*) are significant. &
\end{tabular}

after loading (0 months), after 6 months (6), and after 12 months (12) follow-up visits respectively. The mean values and standard deviations of the MBF in Attachment (2) (Ball attachment) were 66.09 \pm 4.7 , $84.1 \pm 2.01$, and $94.5 \pm 10.8$ immediately after loading (0 months), after 6 months (6), and after 12 months (12) follow-up, respectively, as shown in Table 1. The MBF showed an obvious increase in each single group. There was statistically significant difference $(p<0.05)$ in MBF between Attachment (1) and Attachment (2) immediately after loading ( 0 months), after 6 months (6), and after 12 months (12) follow-up visits. The MBF showed an obvious increase throughout the whole study period, as shown in Figure 7.

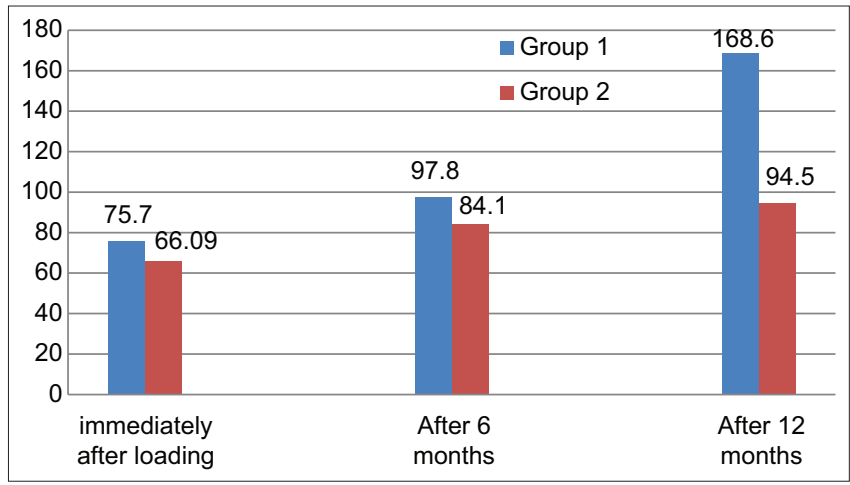

Figure 7: Maximum biting force of Attachment (1) (bollard attachment) and Attachment (2) (ball attachment) immediately after loading (0 months), after 6 months (6), and after 12 months (12) follow-up visits

\section{Discussion}

The main goals of any dental prosthesis are to restore function and esthetics of the patient regardless of any atrophy or resorption. In the cases with resorbed mandibular ridge, it becomes difficult to achieve these goals with the conventional denture. The use of dental implants nowadays for supporting and retaining mandibular dentures has helped to fulfill the functional requirements of the patient with any challenging cases [22].

Placing from two to four implants with attachments can improve the retention and stability of mandibular implant overdentures and can achieve greater support by projecting axial loads into the bone [23].
Interforaminal implant placement has been the choice in most cases to avoid surgical preparation for the ridge and escape from the inferior alveolar injury with satisfaction to the patient needs for a retentive restoration [24].

Randomization in this study in choosing the position of abutment placement either to the right side or the left side is mandatory to diminish the effect of preferable chewing side of the patient.

A split-mouth design was used to evaluate the MBF of the same patient to ignore any other interfering variable that may affect the results.

The use of metal framework in this study was to decrease the possibility of denture fracture especially at the area opposing the abutment and its attachment systems.

Overcontoured waxing up was made at the canine area in both sides to provide sufficient thickness of acrylic base that allowing relief of the fitting surface opposing the abutment without perforation of the denture base.

Ball and socket abutment was used in this study due to its simplicity, ease of handling, minimal chair side time, and relatively low-cost [22].

The Bollard (Poller) is a new resilient telescopic attachment system that is employed in implant supported removable denture cases. It offers better wide force distribution, mechanical durability, reduced denture movement, and increased retention thus improving the masticatory function of the patients [8].

Retention.Sil systems are similar to the elastic impression materials that allow for the ease of insertion and removal of the denture. They also allow for even stress distribution to the supporting structures being a traumatic that increasing the chewing and masticatory function because of the material flexibility [25]. The reduced ability of advanced age patients to adapt to new complete dentures because of their reduced or diminished neuromuscular control can be easily treated with this system. The easy of chair-side pick-up of such system is also one of the main advantages and therefore, patient's comfort, and satisfaction with dentures [26].

Clinical observations promote retention.sil as a suitable matrix product for implant overdenture cases, due to its positive biological, physical, and retention properties. Retention.Sil was introduced based on its chemical composition on PVS that has three options according to the detachment force desired (200, 400 , and $600 \mathrm{gf}$ ). Retention.sil 600 was used in this study because it best suited in the later phases after osseointegration and offers a better retention with the abutment which remains almost constant over time with different attachment systems (ball or Locator attachment system) [12], [27].

Resilient liner housing completely obturates the space found around the abutment, and so it 
minimizes the plaque accumulation and the microbial adhesion that cause peri-implant tissue inflammation, bone loss, and pocket formation. Recent studies considered that resilient denture liner materials can be useful for tissue-supported implant-retained overdenture. The use of resilient silicone lining material for retention resulted in a considerable decrease in the stresses transmitted to the implant and peri-implant bone compared to metal housing [28]. Shock-absorbing ability of soft liner reduces the stress applied to the implants which, in turn, reduces periimplant bone loss [27].

Denture wearers were found to undergo an adaptation process to the new prosthesis, during which the MBF was found to increase considerably after 1 month of use [29].

MBF in mandibular implant-supported overdenture patients is almost twice as much as that of conventional (complete denture) prosthetic patients [30].

The MBF in this study showed significant increase throughout the whole study follow-up period $(0,6$, and 12 months) in both groups and inside every single group which is an indication of better patient adaptation and neuromuscular coordination with the mandibular implant retained overdenture. The results of the current study confirm that mandibular implant retained overdenture with bollard abutment that was retained with the denture by the help of resilient liner "Retention.Sil 600" without housing showed higher MBF and masticatory performance than mandibular implant retained overdenture with ball abutment where the plastic house was picked up by monomer free selfcured acrylic resin.

And our results favoring the bollard attachment over the ball and socket and this can be attributed to the wider flat top surface of the bollard abutments relatively to the ball abutment and this wider flat table help in exerting a higher biting force. Moreover the use of retention.sil soft relining materials may be a factor permitting the patient to perform a higher biting force.

\section{Conclusion}

Within the limitations of this study, it can be concluded that mandibular implant retained overdenture with Bollard abutment that retained with the denture by the help of resilient liner "Retention. Sil 600" without housing have higher biting forces compared to mandibular implant retained overdenture with ball abutment where the plastic house was picked up by monomer free self-cured acrylic resin.

\section{References}

1. Anas El-Wegoud M, Fayyad A, Kaddah A, Nabhan A. Bar versus ball attachments for implant-supportedoverdentures in complete edentulism: A systematic review. Clin Implant Dent Relat Res. 2018,20:243-50. https://doi.org/10.1111/cid.12551

PMid:29071777

2. Glossary of Implant Dentistry III. International Congress of Oral Implantologists; 2017.

3. Burns DR. The mandibular complete overdenture. Dent Clin North Am 2004;48(3):603-23.

PMid:15261796

4. Tokuhisa M, Matsushita $\mathrm{Y}$, Koyano K. In vitro study of a mandibular implant overdenture retained with ball, magnet, or bar attachments: comparison of load transfer and denture stability. Int J Prosthodont. 2003;16(2):128-34. https://doi. org/10.1016/s0022-3913(03)00339-1

PMid:12737242

5. Svetlize CA, Bodereau EF Jr. Comparative study of re-tentive anchor systems for overdentures. Quintessence Int. 2004;35(6):443-8.

PMid: 15202589

6. Luthra R, Sharma A, Kaur P. Implant supported overdenture: A case report. Periodon Prosthodon. 2016;2:2. https://doi. org/10.21767/2471-3082.100018

7. Lachmann S, Kimmerle-Müller E, Gehring K, Axmann D, Gomez-Roman G, Watzek G, et al. A comparison of implant supported bar or ball retained mandibular overdentures: A retrospective clinical, microbiologic, and immunologic study of 10 edentulous patients attending a recall visit. Int J Prosthodont. 2007;20(1):37-42.

PMId:17319360

8. Niedermeier W. 3-year clinical trial of the bollard coping. Z Zahnärztl Imp. 2003;19:99-106.

9. Kimoto S, Kimoto K, Gunji A, Kawai Y, Murakami H, Tanaka $\mathrm{K}$, et al. Clinical effects of acrylic resilient denture liners applied to mandibular complete dentures on the alveolar ridge. J Oral Rehabil. 2007;34(11):862-9. https://doi. org/10.1111/j.1365-2842.2007.01728.x

PMid:17919254

10. Kimoto S, Kimoto K, Gunji A, Kawai Y, Murakami H, Tanaka K, et al. Effects of resilient denture liner in mandibular complete denture on the satisfaction ratings of patients at the first appointment following denture delivery. Nihon Hotetsu Shika Gakkai Zasshi. 2008;52(2):160-6. https://doi.org/10.2186/ jjps.52.160

PMid: 18467785

11. Pisani MX, Malheiros-Segundo Ade L, Balbino KL, de Souza RF, Paranhos Hde F, da Silva $\mathrm{CH}$. Oral health related quality of life of edentulous patients after denture relining with a siliconebased soft liner. Gerodontology. 2012;29(2):474-80. https://doi. org/10.1111/j.1741-2358.2011.00503.x

PMid:21696442

12. Preoteasa $\mathrm{E}$, Imre M, Lerner $\mathrm{H}$, Tancu AM, Preoteasa CT. Narrow Diameter and Mini Dental Implant Overdentures. London: IntechOpen; 2015. p. 978-953. https://doi.org/10.5772/59514

13. Altaf $D$, Nawaz MS, Hassan M, Hassan A, Haseeb M, Malik A. Association of handedness and maximum voluntary bite force on respective side of oral cavity. Int J Dent Oral Sci. 2020;7(11):872-5.

14. Guimarães EA, Cabral AL, Sousa LR, Júnior PC, da Sousa GC, Neto AJ. Influence of body position on maximum bite force. 
Manual Ther Posturol Rehabil J. 2017;15:525.

15. Amid R, Ebrahimi N, Kadkhodazadeh M, Mirakhori M, Mehrinejad P, Nematzadeh F, et al. Clinical evaluation of a new device to measure maximum bite force. Dent Case Rep 2018;2(2):26-9.

16. Schiffman E, Ohrbach R, Truelove E, Anderson G, Goulet JP, List $\mathrm{T}$, et al. Diagnostic criteria for temporomandibular disorders (DC/TMD) for clinical and research applications: Recommendations of the international RDC/TMD consortium network and orofacial pain special interest group. J Oral Fac Pain Headache. 2014;28(1):6-27. https://doi.org/10.1111/ joor.12378

PMid:24482784

17. da Said AV, Takaki PB, Vieira MM, Bommarito S. Relationship between maximum bite force and the gonial angle in crossbite. Dent Oral Craniofac Res 2017;3(5):1-5. https://doi.org/10.15761/ docr.1000215

18. Dıraçoğlu D, Alptekin K, Cifter ED, Güçlü B, Karan A, Aksoy C. Relationship between maximal bite force and tooth wear in bruxist and non-bruxist individuals. Arch Oral Biol. 2011;56(12):156975. https://doi.org/10.1016/j.archoralbio.2011.06.019 PMid:21783173

19. Geckili O, Bilhan H, Mumcu E, Dayan C, Yabul A, Tuncer N. Comparison of patient satisfaction, quality of life, and bite force between elderly edentulous patients wearing mandibular two implant-supported overdentures and conventional complete dentures after 4 years. Spec Care Dent. 2012;32(4):136-41. https://doi.org/10.1111/j.1754-4505.2012.00258.x PMid:22784321

20. Murata H, Taguchi N, Hamada T, Kawamura M, McCabe JF. Dynamic viscoelasticity of soft liners and masticatory function. J Dent Res. 2002;81(2):123-8. https://doi.org/10.1177/0810123 PMid:11827257

21. Hayakawa I, Hirano S, Takahashi Y, Keh ES. Changes in the masticatory function of complete denture wearers after relining the mandibular denture with a soft denture liner. Int J Prosthodont. 2000;13(3):227-31. https://doi.org/10.2186/ prp.3.25

\section{PMid:11203637}

22. Alqutaibi A, Kaddah A. Attachments used with implant supported overdenture. Int Dent Med J Adv Res. 2016;1:1-5.

23. Boven GC, Raghoebar GM, Vissink A, Meijer HJ. Improving masticatory performance, bite force, nutritional state and patient's satisfaction with implant overdentures: A systematic review of the literature. J Oral Rehabil. 2015;42(3):220-33. https://doi.org/10.1111/joor.12241

PMid:25307515

24. Misch CE. Contemporary Implant Dentistry. $3^{\text {rd }}$ ed. Amsterdam, Netherlands: Elsevier; 2008. p. 812-813.

25. Chung $\mathrm{KH}$, Chung CY, Cagna DR, Cronin RJ Jr. Retention characteristics of attachment systems for implant overdentures. J Prosthodont. 2004;13(4):221-6. https://doi. org/10.1111/j.1532-849x.2004.04042.x

PMid:15610542

26. Thompson GW, Kriesel PS. The impact of demographics of aging and the edentulous condition on dental care service. J Prosthet Dent. 1998;79(1):56-9.

PMid:9474542

27. Preoteasa E, Tancu AM, Preoteasa CT. Retention Sil as Silicone Matrices for Implant Overdenture. Bucharest, Romania: Carol Davila University of Medicine and Pharmacy; 2014. https://doi. org/10.25122/jml-2019-0028

28. Kalachev YS, Iordanov PI, Chaprashikian OG, Manohin E. Measurmaent of the magnitude of the occlusal forces during articulation. Folia Med (Plovdiv) 2001;43(1-2):97-100. PMid:15354479

29. Borie E, Orsi IA, Fuentes R, Beltrán V, Navarro P, Pareja F, et al Maximum bite force in elderly indigenous and non-indigenous denture wearers. Acta Odontol Latinoam. 2014;27(3):115-9. PMid:25560689

30. Rismanchian M, Bajoghli F, Mostajeran Z, Fazel A Eshkevari PS. Effect of implants on maximum bite force in edentulous patients. J Oral Implantol. 2009;35(4):196-200. https://doi.org/10.1563/1548-1336-35.4.196

PMid:19813425 